\title{
EL CUENTO COMO HERRAMIENTA DE INTERVENCIÓN
}

\section{Exequiel Guevara}

Escuela Niños Felices, Chile.Fono: +56 45 2922079. Correo electrónico: exequiel.gd@gmail.com

Estimado Sr. Editor:

Para la adquisición de aprendizajes y habilidades lingüísticas, cognitivas, emocionales y sociales que desarrolla el niño antes de su ingreso a la educación básica, una herramienta innegable que disponen todos los agentes involucrados en la enseñanza de los infantes, ya sean profesionales, técnicos o la misma familia, es el cuento.

El cuento, mirado no solamente desde el hecho lúdico y divertido, invita a quien lo lee o escucha a sumergirse en un mundo fantástico, en donde cada persona lo interpreta de manera muy distinta, debido a que contrasta la información presentada con las experiencias adquiridas previamente.

Y es aquí donde surge un primer aporte, ¿Qué sucedería si se le solicita a los niños que conforman un curso que relaten con sus palabras el mismo cuento presentado por sus educadores? Se produciría un intercambio de información impresionante, en donde cada infante relataría su propia historia de lo que iba imaginando mientras oía o leía el cuento.

Otro punto trascendental a mencionar, es que el cuento es una actividad increíblemente eficaz en el reclutamiento de recursos cognitivos y lingüísticos (Borzone, 2005). En primer lugar para poder almacenar la información, el niño en conjunto con poseer la habilidad de sentir por medio de sus sentidos para luego percibir a nivel cortical, debe ser capaz de fijar su atención por un periodo de tiempo para que pueda permitir el paso de la información a la memoria de trabajo, de corto plazo y, si es significativo, a la de largo plazo. Asimismo, y en conjunto al hecho de ir aumentando su vocabulario, se ponen en juego una serie de habilidades lingüísticas, en donde el niño debe ir descifrando casi de manera simultánea al momento del ingreso de la información, a la vez que estructura en una línea temporal y causal los hechos narrados. Junto a lo anterior, se ponen en marcha procesos cruciales en el tratamiento de la información, las llamadas funciones ejecutivas. 
Las funciones ejecutivas son la que nos permiten almacenar y administrar nuestros recursos mentales, así como también permite adaptarnos y solucionar las diversas situaciones que ocurren a lo largo de la vida. Anderson (2002), las subdivide en cuatro grandes bloques interrelacionados entre sí: control atencional, flexibilidad cognitiva, establecimiento de metas y procesamiento de la información, en donde cada uno se sub-divide en tres o cuatro procesos cognitivos, los que si bien no alcanzan un desarrollo pleno hasta la edad adulta, ya se encuentran emergiendo a edades tempranas (Lozano \& Ostrosky, 2011).

A raíz de lo expuesto anteriormente, se invita a que toda persona que realice procesos de intervención o de enseñanza en edades tempranas, utilice el cuento como una herramienta más dentro del abanico de opciones educativas y terapéuticas. Del mismo modo, se sugiere que una vez contado o leído el cuento, se le realicen preguntas al niño ya sea en formato cerrado, en donde se le otorgan alternativas para que responda, o en formato abierto, en donde simplemente se le realiza la pregunta y el niño debe responder utilizando todos sus recursos cognitivos.

\section{Referencias}

Anderson, P. (2002). Assessment and development of executive function (EF) during childhood. Child neuropsychology, 8, 2, 71-82.

Borzone, A. (2005). La Lectura de Cuentos en el Jardín Infantil: Un Medio Para el Desarrollo de Estrategias Cognitivas y lingüísticas. Psykhe, 14, 1, 192-209.

Lozano, A., \& Ostrosky, F. (2011). Desarrollo de las Funciones Ejecutivas y de la Corteza Prefrontal. Revista Neuropsicología, Neuropsiquiatría y Neurociencias, 11, 1, 159-172. 